Chapter Title: Introduction: Devastation and Laughter

Book Title: Devastation and Laughter

Book Subtitle: Satire, Power, and Culture in the Early Soviet State (1920s-1930s)

Book Author(s): ANNIE GÉRIN

Published by: University of Toronto Press. (2018)

Stable URL: https://www.jstor.org/stable/10.3138/j.ctv8bt1cg.6

JSTOR is a not-for-profit service that helps scholars, researchers, and students discover, use, and build upon a wide range of content in a trusted digital archive. We use information technology and tools to increase productivity and facilitate new forms of scholarship. For more information about JSTOR, please contact support@jstor.org.

Your use of the JSTOR archive indicates your acceptance of the Terms \& Conditions of Use, available at https://about.jstor.org/terms

University of Toronto Press is collaborating with JSTOR to digitize, preserve and extend access to Devastation and Laughter 


\section{Introduction: Devastation and Laughter}

Laughter has always been an important element in social processes. The role of laughter is as important as ever in our struggle, the last struggle for the emancipation of human beings.

A.V. Lunacharsky ${ }^{1}$

"We don't have laughter for laughter's sake, simple belly-laughs that bare all teeth, just like we don't have art for art's sake. Here, art and laughter are implements of battle." 2 These words were written in 1938 by graphic satirist Dmitrii Orlov, better known by his pen name Dmitrii Moor. Since the days of the October Revolution, Moor had been prosperously employed as an artist-satirist, producing posters for the state and contributing images to several Soviet satirical journals (Plate 1). For him the harnessing of graphic satire to state propaganda - the belligerent laughter he spoke of - could be nothing but positive. Not only did it allow him to feed and clothe his family (no small feat in a period marked by civil war, famine and dearth), it afforded satire - and therefore satirists - an important social status.

During the same years, Nadezhda Mandelstam occupied a very different position on the Soviet social map. She had joined in deportation her husband, the poet Osip Mandelstam, arrested for the first time in 1934 for composing an epigram that bluntly poked fun at Stalin and then again in 1938, accused this time of counterrevolutionary activities. ${ }^{3}$ In her memoirs of a life half spent in internal exile, forced out of Moscow by the Stalinist regime, she recalled bitterly the prevalence of state-sponsored satire, which she felt had 


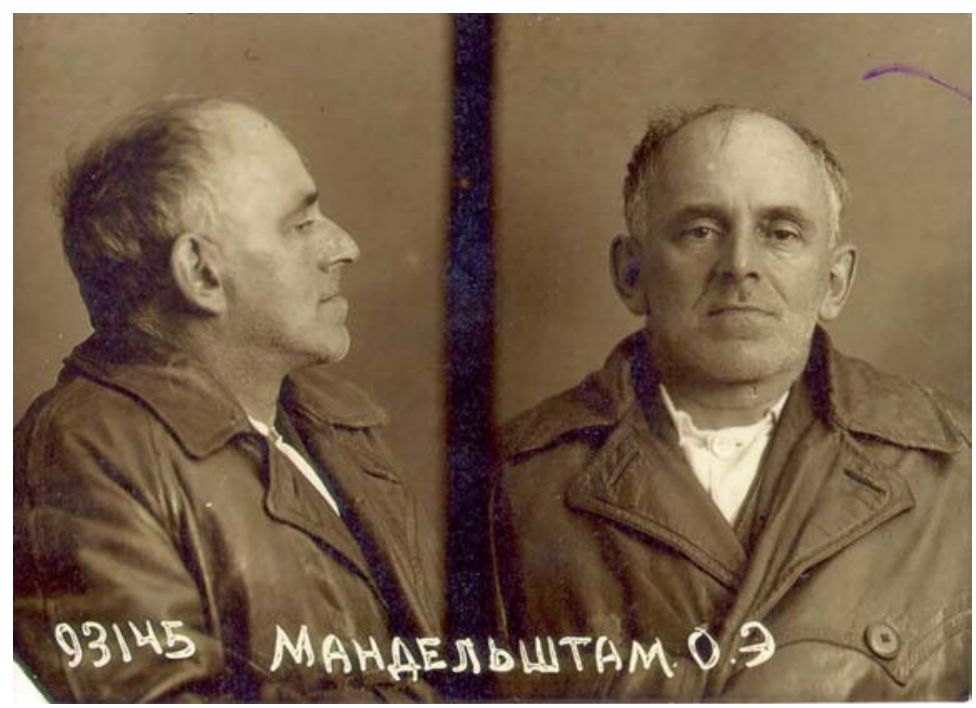

0.1 Police photograph of the poet Osip Mandelstam taken on his arrest in 1938. Part of the David King Collection. Presented to Tate Archive by David King 2016.

become an official sort of laughter at the expense of poetic wit. "In the twenties," she wrote, "humour disappeared altogether, except insofar as it was made to serve, during the next fifty years, as a wellpaid propaganda technique." 4

But laughter, whether it be satirical, humorous, absurd, or otherwise, never disappeared in the Soviet Union. In 1920, in the midst of the Civil War, Anatoly Lunacharsky, then People's Commissar of Enlightenment, marvelled at the resilience of his people and their capacity to find mirth in the everyday: "We live in a hungry and cold country that was recently torn to shreds. Yet, I often hear laughter, I often see laughing faces on the streets." ${ }^{5}$ Among its innumerable forms, there were harmless humorous ditties, kitschy calendars, and "politically correct" plays and animation films. There were also political jokes, oppositional to the regime, whispered behind closed doors. In the 1930s, at the height of the Stalinist purges, these were taken very seriously; they could send their utterer to the forced labour camps of Kolyma. And there was official, state-sponsored satire, put to the service of propaganda. 


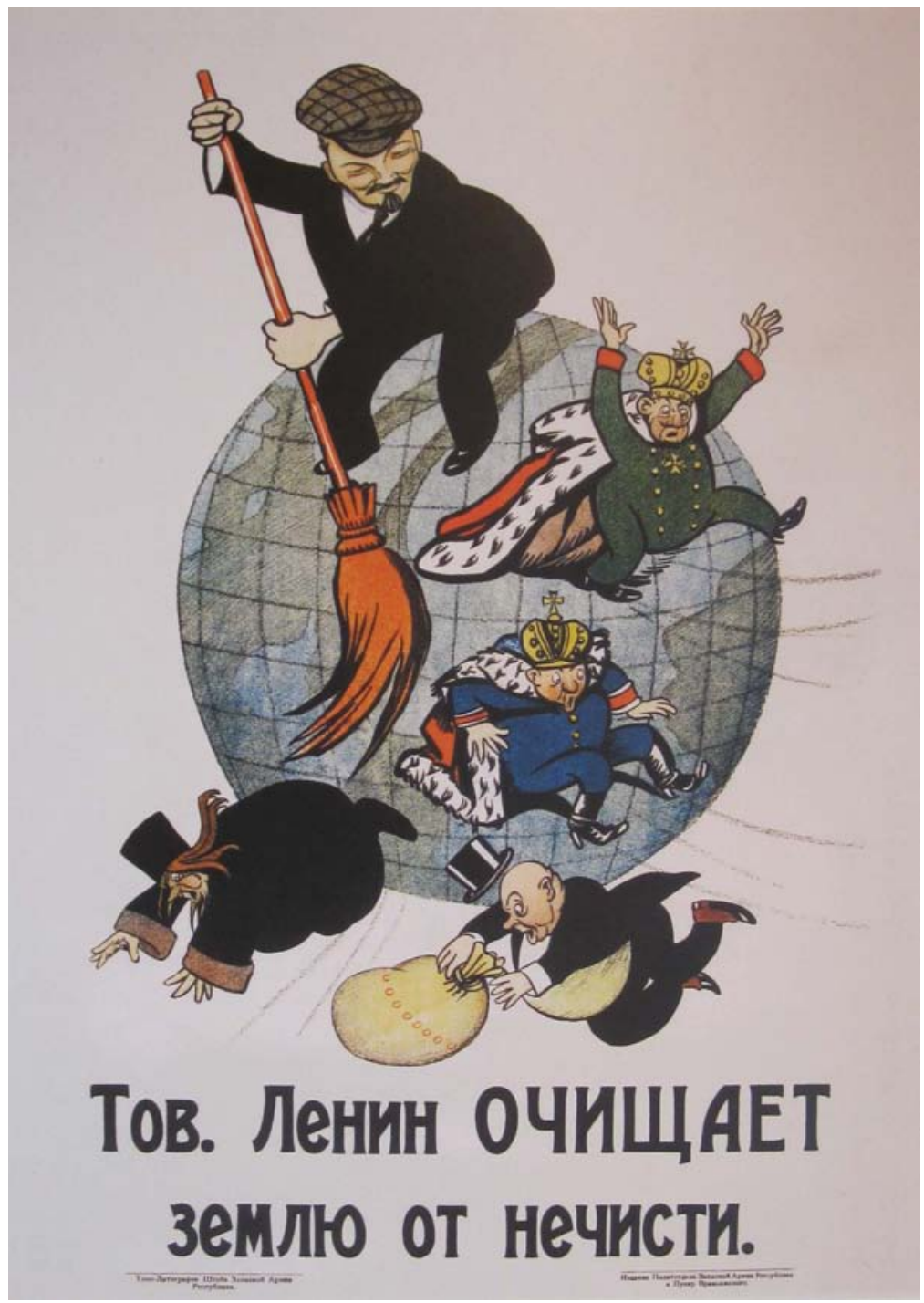

0.2 "Comrade Lenin Is Sweeping the Scum off the Earth," poster by Viktor Deni, 1920. Part of the David King Collection. Presented to Tate Archive by David King 2016. 
The Soviet system produced, in its early years, tremendous amounts of hope, energy, and joy. But it also engendered suffering, repression, and fear. It is against this complex backdrop of devastation and laughter that the subject of this book takes shape.

This study is about Soviet state-sponsored satire in the visual arts, cinema, theatre, and the circus in the 1920s and 1930s. It focuses on visual manifestations of laughter, rather than on the satirical literature of Ilf and Petrov, Mikhail Zoshchenko, Mikhail Bulgakov, or Daniil Kharms, which has garnered some degree of interest from scholars over the past decades.

I started to think about visual uses of satire several years ago when I encountered for the first time the satirical antireligious journal $\mathrm{Bez}-$ bozhnik u stanka (Godless at the Workbench, 1923-31). The aforementioned Dmitrii Moor was this richly illustrated publication's artistic director. Regular contributors included prominent artists, such as Aleksandr Deineka, Mikhail Cheremnykh, and Aleksandr Radakov, who had experimented with abstraction in the 1910s or were to later join the ranks of socialist realism. They frequently maintained parallel "serious" and "unserious" practices. Yet their satirical production is - to this day conspicuously absent from the glossy-paged monographs dedicated to their work. After this initial contact, Soviet satirical images started to appear with greater frequency in my field of vision. In fact, I realized they were everywhere: in journals, posters, films, collages, and even (although less frequently) in paintings and photographs.

The two main motivations for writing this book are to address the scarcity of Soviet visual satire in art historical research and to question certain assumptions about Soviet culture, largely disseminated in scholarship and in mass media. I am a child of the Cold War. Like many of my generation, I have had bleak and drab images of Soviet Russia imprinted onto my retinae from the earliest age. As a teenager, I regularly saw on television people in ratty beige overcoats queuing for bread against grey winter skies. I saw broken-down Ladas on unkempt roads and oversized glasses sitting on the noses of bored bureaucrats. I saw worried faces, gigantic ballistic missiles parading across Red Square, and the rushed evacuation of Chernobyl. Laughter never made the news and Russia did not seem like a fun place at all. As an art historian, I studied the Russian avant-garde - rayonism, suprematism, constructivism - and then socialist realism. For all its utopian impulses and earnestness, Soviet art never seemed much fun either. But as I found out traipsing around Russia for the past few 
decades, the reality is much more complex than it appears from the other side of the globe. I also realized, when I started to think critically about laughter, that it can play various and sometimes apparently incompatible roles.

\section{Theories of Laughter}

There are two main difficulties associated with the study of laughter. The first is rooted in language. Scholars often make no distinction between the humorous, the absurd, the witty, the satirical, the farcical, and the jocular. These are all understood as variants of humour linked by a common purpose, the production of laughter or amusement. As we will see throughout this book, the particular brand of laughter matters greatly. It provides more than a tone or intensity - it is a rhetorical mode, made to produce specific affects and effects. In my general analysis, I have used the word "laughter" as an umbrella term; smekh was in fact the word used most widely in Soviet theoretical and critical writings in the 1920s and 1930s. This preference for "laughter" over "humour" or any other term was no doubt borrowed directly from the title of Henri Bergson's Laughter, first published in French in 1899 as a series of three articles in La revue de Paris, and translated into Russian the following year. Satire, humour, irony, parody, and other key terms will be defined as we go.

The second difficulty is interpretive. Laughter is the fiefdom of deeply cultural and contextual forms and it draws on topical themes, vocabularies, and images. Therefore, early-twentieth-century wit might seem unfunny to our twenty-first-century eyes and intellects. We may not recognize the sources of parodies or know their targets. We may not fully understand the general context or the importance of norms being transgressed in a satirical work. Umberto Eco once remarked, with regard to the telling of jokes, that "what remains compulsory, in order to produce a comic effect, is the prohibition of spelling out the norm. It must be presupposed both by the utterer and by the audience. If the speaker spells it out, he is a fool or a jerk; if the audience does not know it, there is no comic effect." ${ }^{6}$ Obviously, this judicious remark on the art of jokesmanship does not apply to the interpretation of laughter in the context of scholarly research. In fact, the opposite is true.

To unlock the potential richness of laughter in visual works and link them to broader visual, cultural, political, and intellectual frameworks, 


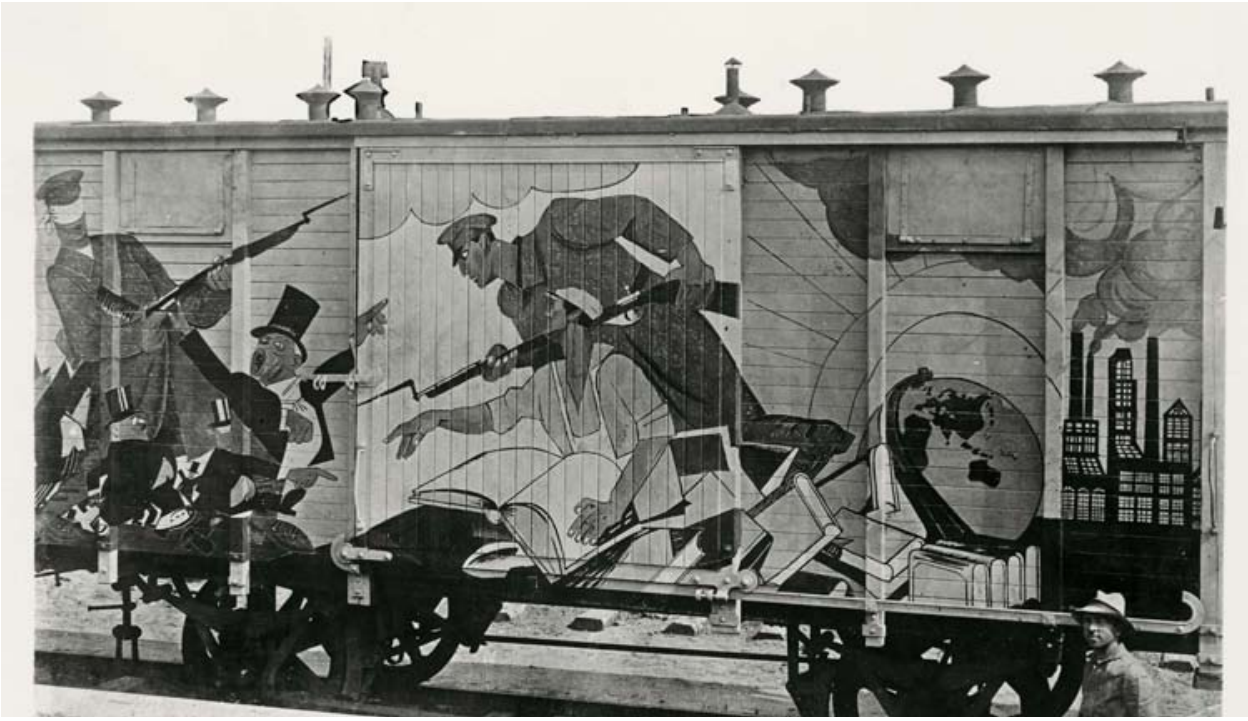

0.3 Agitational train decorated with satirical propaganda played an important role in the acculturation process in the 1920s. Part of the David King Collection. Presented to Tate Archive by David King 2016.

we will need to establish contexts and conduct meticulous descriptions, iconographical analyses and investigations of norms and traditions, as well as examine the formal mechanisms that produce laughter outcomes in a given work. This restitution will always be imperfect, however. It is impossible to recreate for the contemporary viewer the initial affective response that captured those who first saw a given work in full colour, at proper scale, and displayed in its original setting.

Bearing all this in mind, we can gain valuable insight into society from the study of laughter, since it targets everyday practices and values by playing with expectations. It puts the finger on nodes of tension to poke fun at norms and rules, rebel against them, exacerbate potential dissensus, or endorse escapism. It also sheds light on hopes and aspirations, as well as on the dark corners of the human soul, where shame and hatred are relegated. In other words, it amuses, distracts, celebrates, informs, attacks, and chastises; it partakes in complex processes of acculturation. 
Contemporary scholarship on laughter divides theoretical approaches in three main streams: superiority theory, relief theory, and incongruity theory. ${ }^{7}$ Superiority theory goes back to Plato, Aristotle, and Quintilian, who believed humans take pleasure in laughing at deformed, ugly, or morally inferior individuals or at the misfortunes of others. ${ }^{8}$ For Thomas Hobbes, who built on the Aristotelian tradition, "The passion of Laughter is nothing else but a suddaine Glory arising from suddaine Conception of some Eminency in our selves by Comparison with the Infirmityes of others, or with our owne formerly." ${ }^{\prime 9}$ At the turn of the twentieth century, Henri Bergson emphasized the aggressive feelings that also fuel this condescending laughter. "In this sense, laughter cannot be absolutely just. Nor should it be kind-hearted either. Its function is to intimidate by humiliating. Now, it would not succeed in doing this, had not nature implanted for that very purpose, even in the best of men, a spark of spitefulness or, at all events, of mischief."10

Relief theory appeared in the nineteenth century in the work of Herbert Spencer. Spencer approached laughter from the angle of psychophysiology. He understood it as "the discharge of arrested feelings into the muscular system" that happens when a concentrated subject is suddenly distracted or liberated from stress. "Laughter naturally results only when consciousness is, unawares, transferred from great things to small."11 Sigmund Freud's work in Jokes and Their Relation to the Unconscious (1905) shifted relief theory towards the unconscious. ${ }^{12}$ Freud argued that laughter occurs as the symptom of an economy of psychic energy that is achieved when forbidden thoughts or feelings (that would usually need to be repressed in deference to society) are expressed as a joke.

Finally, the incongruity theory can be traced to Aristotle's Rhetoric, but it was rediscovered and expanded upon periodically over the centuries by Francis Hutcheson, Immanuel Kant, Arthur Schopenhauer, Søren Kierkegaard, Arthur Koestler, and others. ${ }^{13}$ While the previous theories can be considered affective, incongruity theory can be understood as cognitive or structural. It proposes that laughter arises from the failure of perceptions to match expectations. Schopenhauer emphasized the element of surprise caused by the mismatch: "The greater and more unexpected this incongruity in the apprehension of the person laughing, the more violent will be this laughter." ${ }^{14}$ In the context of visual satire, incongruities leading to bursts of laughter will be found in the subject matter of a given work (either intrinsically in relation to its context or other representations), but they will also arise from its formal 
components: composition, style, colour, scale, and liberties taken with conventions of representation.

These three main approaches are by no means exhaustive. Other theories have been developed to address, for example, a presumed evolutionary advantage of people graced with a good sense of humour, ${ }^{15}$ the benevolence of laughers in certain situations (what Michael Billig calls "the nice guy theory"), ${ }^{16}$ or the morphological aspects of laughter, as in Vladimir Propp's formalist method. ${ }^{17}$ Furthermore, superiority, relief, and incongruity theories are not impervious to one another. Freud speaks of the cruelty and tendentiousness of laughter, and the feeling of self-importance it may provide; Spencer mentions how incongruity may be the source of emotional demobilization, and Hobbes comments on the potential relief caused by the expression of disdain over others. The Russian understanding of laughter that emerged and evolved in the early part of the twentieth century, the backbone of this book, borrows from all three theories.

\section{Weapons and Tools}

If, as Moor observed, Soviet laughter is an implement of battle, it then needs to be considered in terms of its rhetorical potential, as intentional and conscious communication holding certain impelling qualities. In his book Institutio Oratoria, Quintilian adopted this point of view. He argued orators should seek the production of laughter in their speeches for its effectiveness as a means of persuasion: "I now turn to a very different talent, namely that which dispels the graver emotions of the judge by exciting his laughter, frequently diverts his attention from the facts of the case, and sometimes even refreshes him and revives him when he has begun to be bored or wearied by the case."18 Three crucial points about the use of laughter as a rhetorical device are brought to the fore in Quintilian's account. First, skilled orators can use laughter to alleviate tension; it may also ease the discussion of emotional or rebarbative topics. Second, used judiciously, laughter can be effective at creating diversions, or shifting the audience's attention away from facts that may hinder the speaker's objectives. Third, if the audience lose interest, laughter holds the potential to draw their attention back to the topic at hand.

But there is more. Under the guises of laughter certain things can be expressed that would otherwise be silenced altogether. Furthermore, particular cognitive or signifying relationships can be created within a "community of laughers." For example, irony allows the audience to engage actively in the (re)construction of meaning, as they figure out that the 
orator is saying the opposite of what she actually means. This waggish investment in signification processes creates a bond between the speaker and her public, who need to be "in the know" to a certain degree to understand the ironic twist. Parody functions differently: it mimics a form while displacing its intent. It allows the audience to playfully rework conceptions about people, ideas, and things they might have previously taken for granted. As the parodic configuration circulates, it then contaminates the source from which it draws. For those exposed to the parody, the signifying integrity of the original is therefore compromised. Satire functions as a broader category that can integrate either irony and parody or both (or none). It has very specific goals: to destroy, punish, or correct. By ridiculing its subject, it aims to discredit it, to reveal inconsistencies, vices, and ineptitudes. The desired effect is either the eventual rejection by the audience of the target of satire or the reformation of the shamed victim.

Rhetoric appeals to reason - and to passion. Therefore, for laughter to be effective in a propaganda context, ideology needs to combine with affect: fear, anger, contempt, distress, disgust, interest, shame, surprise, but also joy or amusement. Affects are adaptive responses to external stimuli. While they can - and do - draw on the cognitive and other information-processing systems in the brain, they have a much more immediate function, which has lead scholars to describe them as extra-textual and extra-iconographic: "as such, affects are not to do with knowledge or meaning; indeed, they occur on a different asignifying register." 19 Without subscribing to this mind / body split that would enable us to understand affects as autonomous, let's just say that as opposed to fully articulated interpretations, affects can take place at the threshold of awareness. ${ }^{20}$ In other words, affective responses - rooted in instinct as well as in experience of fear or pleasure - occur as reflex and are later modulated by more complex thought processes. They contribute a significant psychophysiological dimension to the layered character of interpretation. While the turn to affect is relatively recent in humanities scholarship, it is Bergson - along with Baruch Spinoza, William James, and Freud - who stands as a philosophical precursor of affect theory. His writings were readily available in Russia during the first decades of the twentieth century; and they were greatly influential on early Soviet artistic and intellectual production, including the theorizations of laughter. ${ }^{21}$

Affective responses are precisely what differentiate the workings of artistic and satirical works of propaganda from straightforward, earnest ones. In the 1920s, for example, the satirical antireligious journal Bezbozhnik $u$ stanka coexisted with several "serious" antireligious and atheist publications, including Bezbozhnik (Godless, 1923-41) and Ateist 


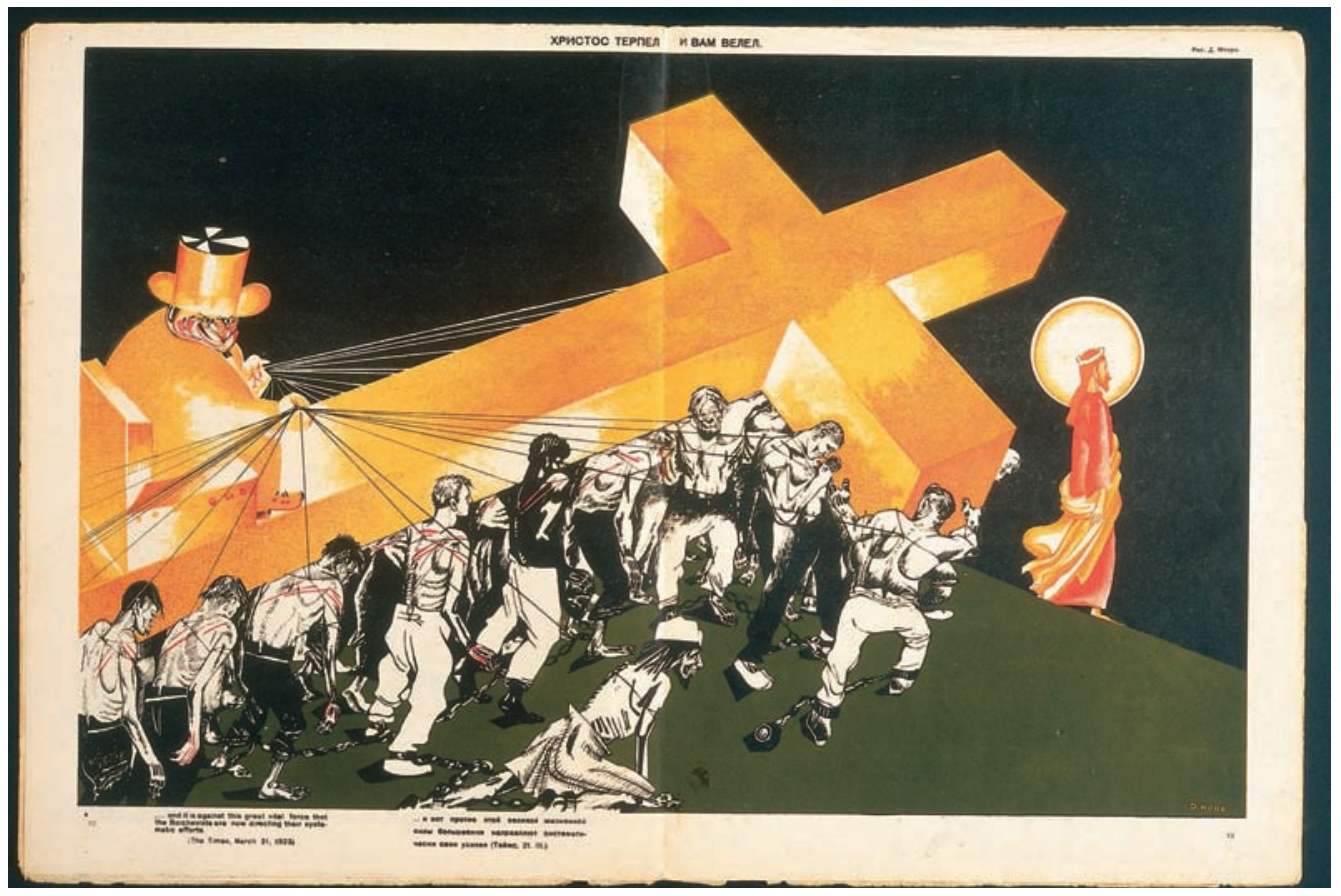

0.4 "Christ suffered for you and showed you the way," centrefold by Dmitrii Moor for the journal Bezbozhnik u stanka, Nos. 9-10, 1923. Part of the David King Collection. Presented to Tate Archive by David King 2016.

(The Atheist, 1922-30). The latter two provided their readers with rigorous argumentation denouncing all religions as historical constructions, miracles as fallacies, and religious institutions as exploitative. These journals were meant to add water to the atheist mill and supply antireligious activists with arguments they could then serve to their audiences. But what Bezbozhnik u stanka could do that these other journals could not was to drive its viewers into a circuit of deep feeling and response. Bezbozhnik u stanka stirred up affect: indignation, hatred, or shame at having been duped in the past. It propelled the viewer into a situation, a state of being, intensity, passion, or empathy. It shifted the critique from the intellect to the experienced, the felt, the lived, and this is precisely why it became so successful as an "implement of battle." And indeed, for Gilles Deleuze and Félix Guattari, "Affect is the active discharge of emotion, the counterattack ... Weapons are affect and affects weapons." 22 
During the years that followed the 1917 October Revolution, remarkable social changes occurred as Russia shifted from a tsarist, theocratic, and capitalist country to a Bolshevik, atheist, and socialist one. This profound transformation entailed more than the nationalization of banks, industry, and private property. It required the shredding of the established social order and the creation of a new, socialist master narrative, a process that spilled onto every plane of public and private life. Under the guidance of the state and its People's Commissariat of Enlightenment, Soviet citizens were called upon to rework their relation to history, the collective, and the everyday. No ideological rock was left unturned with regard to consumption, work, spirituality, knowledge, and the body. In the course of this acculturation process that characterizes early Soviet Russia, sharpened weapons and tools became indispensable. These took the shape of words, images, symbols, rituals, and representations of all kinds. They were used by politicians, theoreticians, and artists to destroy the old, making way for the foundation of new Socialist Russia. Among these, visual satire played a prominent role.

In A Thousand Plateaus, Gilles Deleuze and Félix Guattari pointed out that "a distinction can always be made between weapons and tools on the basis of their usage (destroying people or producing goods). But although this extrinsic distinction explains certain secondary adaptations of a technological object, it does not preclude a general convertibility between the two groups, to the extent that it seems very difficult to propose an intrinsic difference between weapon and tool." ${ }^{23}$ In the Russian language, the corresponding words are oruzhie (weapon) and orudie (tool). While they originated from different etymological roots, the shifting character highlighted by Deleuze and Guattari is nevertheless reflected in their current usage. Oruzhie came from the verb rugat (Slavic root rog), which means to scold, insult, mock. Orudie originally meant "work," "instrument," "equipment," and derives from the Slavic root "red." However, their phonetic proximity was the cause of semantic contamination during the eighteenth century. Oruzhie then developed a new signification, as a hostile means to proceed, or a tool for destruction. ${ }^{24}$ Furthermore, as we will see in the first chapter of this book, in early Soviet writings on laughter, the two words are used almost interchangeably. Satire, in particular, is understood as holding the potential to destroy petit bourgeois attitudes, wipe out superstitions, and punish opportunism, while simultaneously structuring appropriate responses to internal and external threats and contributing to the overall socialist construction of the new. All this is achieved through the rhetorics of laughter. 


\section{Overview of the Book}

In 1930, Anatoly Lunacharsky, People's Commissar of Enlightenment from 1917 to 1929, set up a government commission to study satirical genres in literature, visual arts, music, theatre, and film. He was himself working on a book manuscript provisionally titled "Laughter as a Weapon in Class Struggle," which he never completed. Because of his administrative appointment, Lunacharsky was the principal patron of the arts in the early Soviet period and the main middleman between political leaders such as Vladimir Lenin, Leon Trotsky, and Joseph Stalin on the one hand, and artists such as Vladimir Mayakovsky, Kazimir Malevich, Marc Chagall, Aleksandr Rodchenko, Vassilii Kandinsky, Sergei Eisenstein, and Vsevolod Meyerhold on the other. Throughout his career as commissar, Lunacharsky was instrumental in the production of much satirical work through the allocation of government contracts and commissions to artists. He also wrote art criticism and theoretical texts that encouraged the use of satire and humour by Soviet artists, as weapons against enemies of the regime and as tools for acculturation and social change in the context of the emerging Soviet Union. This work, inspired by prevalent theories of laughter (mainly those of Freud, Bergson, Spencer, Sully, and Lipps), revisits them through the lens of Marxism and translates them into a very specific Soviet language and worldview. Although these texts were originally published in Soviet journals and later reprinted in Soviet anthologies of Lunacharsky's writings, they remain virtually unknown. Chapter 1, "Anatoly Lunacharsky and the Power of Laughter," offers a historical and critical study of Lunacharsky's theoretical work on laughter.

Early Soviet interest in a political culture of satire influenced popular art forms and media, from literature to painting and music, from theatre to cinema and the circus. But its most pervasive visual expression was without a doubt print culture, as satire became ubiquitous in broadsheets, posters, periodicals, and books that disseminated mass propaganda in the early years of the regime. Print culture had been harnessed to mould public opinion and collective self-image for centuries in Russia as elsewhere. In Soviet Russia, the mass reproduction of images and text was understood as a tool that could play a considerable role in popular mobilization and acculturation. Chapter 2, "Soviet Satirical Print Culture: A Serious Affair," highlights the crucial importance of print culture as a support for visual propaganda. It does so by tracing a history of Soviet illustrated satirical journals and Civil War-time posters. 
Chapters 3 and 4 build on the preceding one, but reflect on the specificity of the circus, theatre, and cinema, about which Lunacharsky wrote a great deal, and which the Soviet government also considered important means for propaganda and acculturation. There is, however, one important difference between these forms and the ones discussed in chapter 2. Most circus acts and theatre plays shown in Russia in the 1920s had been written and choreographed before the Revolution. Similarly, during the period, most cinemas were privately owned and showed imported films (Charlie Chaplin and Mary Pickford comedies being particularly appreciated). This caused Lunacharsky, in a text dealing specifically with humour and satire in cinema, to nuance his enthusiasm for the use of laughter, and distinguish between socialist and bourgeois (and potentially dangerous) satire. These two chapters also examine the gradual constitution of a Soviet "satirical scene," the decline of satire in the late 1920s, and the efflorescence of optimistic comedies produced in the early 1930s for the stage and the silver screen, in particular films by Grigory Aleksandrov and Ivan Pyryev.

While theatre and cinema can be considered literary forms from the point of view of play/screen writing, the emphasis here will be on scenography and how the visual can be exploited for satirical purposes in these mediums. And indeed, as Richard Taylor astutely pointed out with regard to films, during the 1920s "cinema was, of course, still silent. It was therefore a purely visual medium of communication and of necessity combining simplicity with directness in its appeal to mass audiences." 25

The fifth chapter, "The Strategies and Targets of Satire," can be considered a methodological one. Here, I identify various strategies developed and adopted by Soviet satirists in the visual arts - including the visual aspects of circus, theatre, and cinema. These strategies can be grouped into four broad categories: caricature, collage, parody, and irony. After defining these terms and determining how each functions pragmatically in relation to the vaster genre of satire, the chapter moves on to three case studies that highlight the scapegoats and types of subject matter most fertile for Soviet satirical practices, and the broader goals artists aimed at through their sardonic treatment of a given theme. These are the so-called Campaign against the Everyday, the antireligious crusade, and the drive against Trotsky and Trotskyism.

Several artists worked simultaneously in satirical and earnest genres, depending on the objectives that shaped the artworks they were producing. The final chapter of this book, "The Rhetorics of Satire and 
Socialist Realism," examines early Soviet debates around satire and the notion of realism in order to propose that the use of humour and satire offered artists alternative and complementary rhetorical modes in the context of propaganda art. While the avant-garde and socialist realism were necessarily forward looking and utopian in their goals and strategies, satire and humour afforded artists the means to critically examine past and present subjects, themes, and practices.

The book concludes with a translation of one of Lunacharsky's key texts, "On Laughter" (1931), a speech given on 30 January 1931 during the inaugural meeting of the Commission for the Study of Satirical Genres at the Academy of Sciences of the USSR. It offers a summary of the theorization of laughter Lunacharsky developed over roughly two decades, and that underpinned public debates about Soviet satire in the 1920s and early 1930s.

\section{Anatoly Lunacharsky and the Soviet Satirical Scene}

An important figure crosses the pages of this book and guides the reader through different aspects of Soviet state-funded laughter. It is that of Anatoly Vassilievich Lunacharsky.

Born in 1875, Lunacharsky became a Marxist at the age of fifteen. Interested in philosophy, he pursued his studies in Switzerland, France, and Italy, reading Marxist theory, French materialism and phenomenology, as well as German nineteenth-century idealist philosophy. He was particularly drawn to the teachings of critical positivists Richard Avenarius and Ernst Mach, and to Henri Bergson's metaphysics of experience. While in Europe, he met prominent socialists including Rosa Luxemburg, Leo Jogiches, Georgii Plekahnov, Alexandr Bogdanov, Leon Trotsky, and Vladimir Lenin, and joined the Russian Social Democratic Labour Party. In 1903 the party split into Bolsheviks, led by Vladimir Lenin, and Mensheviks, who followed Julius Martov. Lunacharsky sided with the Bolsheviks. When the Bolsheviks, in 1908, divided into Lenin's followers and those who supported Bogdanov, Lunacharsky joined the second group. With Bogdanov and Maxim Gorky, Lunacharsky then contributed to the elaboration of the "God-building" theory (bogostroitelstvo), which was immediately denounced by Lenin in his book Materialism and Empiriocriticism (1909).

Like many exiled Russian Marxists, Lunacharsky returned to Russia in February 1917. The day following the October Revolution, he was appointed People's Commissar of Enlightenment and remained in that 


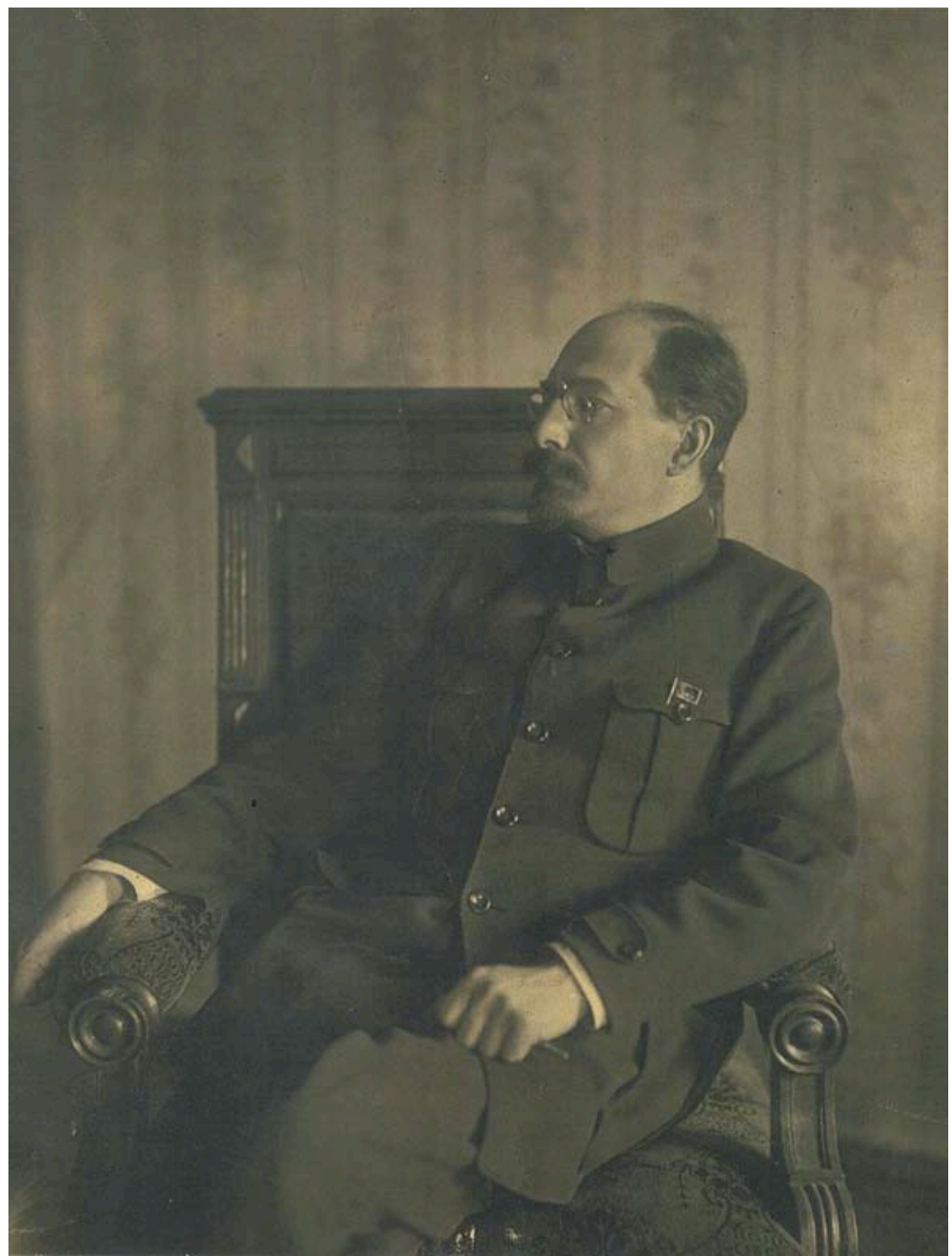

0.5 Portrait of Anatoly Lunacharsky, 1920s. Lunacharsky was People's Commissar of Enlightenment from 1917 to 1929. Part of the David King Collection. Presented to Tate Archive by David King 2016. 
position until 1929. This function entrusted him with oversight of Soviet propaganda, education, and the arts. Known to be an art connoisseur and a shrewd critic, he was clearly the right man for the job. But his liberal ways and his broad interests in psychology, affect, phenomenology, and idealism often sparked misgivings in more orthodox Bolsheviks; they also periodically put him at odds with Lenin.

So why did Lenin appoint Lunacharsky to the key position of People's Commissar and keep him on, despite all their differences? Lunacharsky was smart, sensitive, a brilliant orator, and a passionate defender of the new. Lenin trusted and esteemed him. As he put it to the Soviet writer Viktor Shulgin in 1920: "I advise you also to respect him. He is drawn towards the future with his whole being. That is why there is such joy and laughter in him. And he is ready to share that joy and laughter with everyone." 26

With his appointment as commissar, Lunacharsky found himself in the position of needing to pull together a bureaucratic team from scratch. The call was immediately sent out to all educators and artists. Those who had been close to the pre-revolutionary cultural institutions remained cautious. They essentially refused to cooperate. The artists who chose to join the People's Commissariat of Enlightenment all had certain things in common. They were young, they were forward thinking, they felt sympathy for the regime, they nurtured ambitions for the social role of art - and most already knew each other, for having frequented Saint Petersburg's and Moscow's avant-garde circles and their futurist cabarets.

Many of these also became the protagonists of a Soviet satirical scene during the 1920s - and now of this book. They include, among others, dynamic personalities such as poet Vladimir Mayakovsky, film-maker Sergei Eisenstein, and theatre director Vsevolod Meyerhold. Their friendships and collaborations influenced their creative work - across the mediums - as they shared satirical themes, iconography, and strategies for inducing laughter.

This book is about the deliberate use of laughter for purposes of acculturation in Soviet Russia in the 1920s and 1930s. It was designed to showcase primary sources: decrees, statements, and debates, as well as artworks in a variety of mediums. Indeed, the main arguments that structure this book are made by the protagonists of the story told here: Anatoly Lunacharsky, Vladimir Mayakovsky, Mikhail Koltsov, and many others. 